\title{
Inhibiting the gastric burst release of drugs from enteric microparticles: the influence of drug molecular mass and solubility
}

\begin{tabular}{|r|l|}
\hline Journal: & Journal of Pharmaceutical Sciences \\
\hline Manuscript ID: & 09-629.R1 \\
\hline Wiley - Manuscript type: & Research Article \\
\hline Date Submitted by the \\
Author: & $11-$-Feb-2010 \\
\hline Complete List of Authors: & $\begin{array}{l}\text { Alhnan, Mohamed; The School of Pharmacy, Pharmaceutics } \\
\text { Cosi, Daniele; The School of Pharmacy, Pharmaceutics } \\
\text { Murdan, Sudaxshina; The School of Pharmacy, Pharmaceutics } \\
\text { Basit, Abdul; The School of Pharmacy, Pharmaceutics }\end{array}$ \\
\hline Keywords: & $\begin{array}{l}\text { Diffusion, Dissolution, Distribution, Emulsion, In vitro models, } \\
\text { Microencapsulation, Microparticles, Polymers }\end{array}$ \\
\hline \multicolumn{2}{|l}{} \\
\hline
\end{tabular}

\section{S ScholaroNE \\ Manuscript Central}


Inhibiting the gastric burst release of drugs from enteric microparticles: the influence of drug molecular mass and solubility

Mohamed A. Alhnan, Daniele Cosi, Sudaxshina Murdan and Abdul W. Basit ${ }^{*}$

Department of Pharmaceutics, The School of Pharmacy, University of London, 29/39 Brunswick Square, London WC1N 1AX

Tel.: +442077535865

Fax: +44 2077535865

E-mail Address: abdul.basit@pharmacy.ac.uk

${ }^{*}$ Corresponding author 


\begin{abstract}
Undesired drug release in acid medium from enteric microparticles has been widely reported. In this paper we investigate the relative contribution of microparticle and drug properties, specifically microsphere size and drug's molecular weight and acid solubility, on the extent of such undesired release. A series of nine drugs with different physicochemical properties were successfully encapsulated into Eudragit S and Eudragit L microparticles using a novel emulsion solvent evaporation process. The process yielded spherical microparticles with a narrow size distribution $(25-60 \mu \mathrm{m}$ and 35-55 $\mu \mathrm{m}$ for Eudragit L and Eudragit S microparticles respectively). Upon incubation in acid medium ( $\mathrm{pH}$ 1.2) for $2 \mathrm{~h}$, the release of dipyridamole, cinnarizine, amprenavir, bendroflumethiazide, budenoside, prednisolone from both Eudragit microparticles was less than $10 \%$ of drug load and conformed with USP specification for enteric dosage forms. In contrast, more than $10 \%$ of the entrapped paracetamol, salicylic acid and ketoprofen were released. Multiple regression revealed that the drug's molecular weight was the most important factor that determined its extent of release in the acid medium, while its acid solubility and microsphere's size had minor influences.
\end{abstract}

Keywords: Microspheres, delayed release, enteric polymers, methacrylic polymers, gastric resistance, colonic delivery. 


\section{INTRODUCTION}

The last two decades witnessed the emergence of microencapsulation technology in pharmaceutical formulations ${ }^{1,2}$, which provided a unique platform for delayed and sitespecific oral drug delivery ${ }^{3}$. Modified release microparticles provide several advantages over conventional enteric and delayed release formulations such as larger surface area, potentially more uniform gastric emptying, and a more consistent drug release profile. Unfortunately, the particulate nature and large surface area are accompanied by a major challenge: the inhibition of drug release until the target site is reached. In in vitro dissolution tests, enteric formulations may release no more than $10 \%$ of their drug content during a two-hour incubation in $0.1 \mathrm{~N} \mathrm{HCl}$, and subsequently should release more than $80 \%$ of their drug content within $45 \mathrm{~min}$ of changing the dissolution medium to intestinal conditions. While drug release in intestinal conditions is easily achieved given that readily suspended microparticles have a large surface area, minimising/inhibiting drug release in acidic conditions has proven challenging, and insufficient control of drug release from microparticles in acid media has been reported ${ }^{4-10}$.

It is commonly assumed that the microparticles' surface area is the major factor influencing drug release from matrix microparticles ${ }^{11,12}$. This is in contrast to a previous report by our group which showed that reducing the size of Eudragit $S$ microparticles by two thirds did not alter prednisolone release in the acidic medium ${ }^{13}$. Very little attention has been given to the chemical properties of the drug molecule itself. Silva and Ferreira ${ }^{7}$ used an empirical approach to explore the major factors affecting drug release from microparticles and suggested that high molecular weight and poor drug solubility in acid favours low drug release in acid medium. We have shown that the control of drug release was not necessarily influenced by drug distribution within the microparticle or by high drug solubility in acid ${ }^{14}$. Nevertheless, the relative importance of all these factors is still unclear.

The aim of the work described in this paper was therefore to explore the relative importance of three drug and particle properties that have been directly related to drug release in gastric conditions ${ }^{6,7,15}$, namely, drug molecular weight and its solubility in acid, and microsphere size. Using an efficient o/o emulsion solvent evaporation method developed in our laboratory ${ }^{13,16}$, small uniform-size microparticles loaded with one of nine drug molecules of different physicochemical properties were produced using two different 
$\mathrm{pH}$ responsive polymers; Eudragit $\mathrm{S}$ and Eudragit $\mathrm{L}$ ( $\mathrm{pH}$ thresholds 7.0 and 6.0 respectively). In addition, multiple regression was used to investigate the relative importance of the $3 \mathrm{drug} / \mathrm{microsphere} \mathrm{properties} \mathrm{and} \mathrm{to} \mathrm{explore} \mathrm{the} \mathrm{limitations} \mathrm{of} \mathrm{pH}$ responsive matrix microparticles.

\section{MATERIALS AND METHODS}

\section{Materials}

Paracetamol was supplied by Knoll AG (Ludwigshafen, Germany) and prednisolone was obtained from Sanofi-Aventis, (Romainville, France). Budenoside and amprenavir were gifts from Astra Zeneca (UK) and GlaxoSmithKline (UK) respectively. Ketoprofen, salicylic acid, dipyridamole, cinnarizine, bendroflumethiazide, sorbitan sesquioleate (Span 83, Arlacel 83) and liquid paraffin were purchased from Sigma-Aldrich, (Poole, UK). Polymethacrylate polymers, Eudragit $\mathrm{S}$ and L, were generously provided by Evonik Degussa Chemicals (Darmstadt, Germany).

\section{Preparation of microparticles}

Drug loaded Eudragit $\mathrm{S}$ or Eudragit L microparticles were prepared as reported previously ${ }^{16}$. Briefly, $0.3 \mathrm{~g}$ of drug (indomethacin, paracetamol, salicylic acid, ketoprofen, naproxen, prednisolone, budenoside, bendroflumethiazide, amprenavir or dipyridamole) and $3 \mathrm{~g}$ of polymer (Eudragit $\mathrm{S} / \mathrm{L}$ ) were dissolved in $30 \mathrm{ml}$ of absolute ethanol. The resulting solution was emulsified into $200 \mathrm{ml}$ liquid paraffin containing sorbitan sesquioleate (Span 83) (1\% w/w) as the emulsifier by stirring at a speed of $1000 \mathrm{rpm}$ (Heidolph RZR1 stirrer, Heidolph Instruments, Schwabach, Germany) for 18 hours at room temperature. Solidified microparticles were collected by vacuum filtration, followed by washing three times using fresh batches of $50 \mathrm{ml} n$-hexane. Due to cinnarizine's low solubility in ethanol, the drug and the polymer (Eudragit S or Eudragit L) were dissolved in $30 \mathrm{ml}$ of a mixture of ethanol: acetone $(1: 1 \mathrm{v} / \mathrm{v})$ and microparticles were prepared as above.

\section{Microspheres size analysis}

The volume median diameter of each microparticle formulation suspended in $0.1 \mathrm{~N} \mathrm{HCl}$ was measured in triplicate using laser light scattering using a Malvern Mastersizer 2000 with a $45 \mathrm{~mm}$ lens (Malvern Instruments Ltd., Malvern, UK). Span of microsphere size was calculated as $[\mathrm{D}(\mathrm{v}, 0.9)-\mathrm{D}(\mathrm{v}, 0.1)] / \mathrm{D}(\mathrm{v}, 0.5)$ where $\mathrm{D}(\mathrm{v}, 0.9), \mathrm{D}(\mathrm{v}, 0.5)$ and $\mathrm{D}(\mathrm{v}, 0.1)$ are the 


\section{Differential Scanning Calorimetry}

A DSC 7 Differential Scanning Calorimeter (PerkinElmer Instruments, Beaconsfields, UK) calibrated with indium, was used to assess the presence of crystalline drug in Eudragit $\mathrm{S}$ and Eudragit L microparticles. Microparticles (3-5 mg) were accurately weighed and placed in non-hermetic aluminum pan. Before starting the thermo scan, an isothermal period at $100{ }^{\circ} \mathrm{C}\left(90^{\circ} \mathrm{C}\right.$ for ketoprofen microparticles) was applied for $5 \mathrm{~min}$ (to eliminate residual water content), then the samples were cooled and scanned from $50{ }^{\circ} \mathrm{C}$ to $200{ }^{\circ} \mathrm{C}$ at a rate of $10{ }^{\circ} \mathrm{C} / \mathrm{min}$. Pyris Thermal Analysis Software was used to record and analyze the data.

\section{Drug encapsulation efficiency in microparticles}

Drug loaded microparticles $(50 \mathrm{mg}$ ) were dissolved in $50 \mathrm{ml}$ methanol. The resulting solution was then diluted 10 times with $\mathrm{HCl} 0.1 \mathrm{~N}$ (for neutral and basic drugs) or with phosphate buffer pH 7.4 (for acidic drugs). Samples were filtered using a $0.22 \mu \mathrm{m}$ Millex filter and assayed spectrophotometrically. UV-Vis absorbance was measured using spectrophotometer at $\lambda_{\max }=243,301,254,245,246,254,263$, and $280 \mathrm{~nm}$ for paracetamol, salicylic acid, ketoprofen, prednisolone, budenoside, bendroflumethiazide, amprenavir, and dipyridamole respectively. The encapsulation efficiency of cinnarizine was determined by dissolving $50 \mathrm{mg}$ of microparticles in $50 \mathrm{ml}$ methanol; $10 \mathrm{ml}$ was taken and $0.1 \mathrm{M} \mathrm{HCl}$ was added to precipitate the polymers and made up to $100 \mathrm{ml}$. Samples were filtered through $0.22 \mu \mathrm{m}$ Millex filters and $3.75 \mathrm{ml}$ of the filtrate was added to $5 \mathrm{ml}$ of acetonitrile followed by the addition of $1.25 \mathrm{ml}$ of triphosphate buffer. Cinnarizine was assayed using Hypersil column Thermo Scientific (Runcorn, UK). A Hewlett-Packard 1050 
series HPLC system (Agilent Technologies, UK) supplied with Waters 470 Millipore fluorescence detector (Milford, MA, USA) was utilized to detect samples. The mobile phase, consisting of acetonitrile $(70 \% \mathrm{v} / \mathrm{v})$ and $10 \mathrm{mM}$ potassium dihydrogen phosphate buffer $(30 \% \mathrm{v} / \mathrm{v})$, was eluted at a flow rate of $1 \mathrm{ml} / \mathrm{min}$. The injection volume was $10 \mu \mathrm{l}$, and the fluorescence detector employed an excitation wavelength of $249 \mathrm{~nm}$ and emission wavelength of $311 \mathrm{~nm}$.

For each formulation, 3 different batches were assessed. Drug encapsulation efficiency was calculated as:

$$
\text { encapsulation efficiency }=\frac{\text { measured mass of drug in microparticles }}{\text { theoretical mass of drug in microparticles }} \times 100
$$

Eq.1

\section{Drug solubility in acidic medium}

In order to assess the influence of the drug's solubility in acid on its release, the solubility of all encapsulated drugs in acidic medium were assayed. An excess amount of drug was added to $10 \mathrm{ml}$ of $\mathrm{HCl} 0.1 \mathrm{~N}$ solution and shaken for 24 hours at $200 \mathrm{rpm}$ and $37{ }^{\circ} \mathrm{C}$. The saturated solutions were filtered ( $0.22 \mu \mathrm{m}$ Milleux syringe filters), diluted as appropriate, and UV absorbance was measured at $\lambda_{\max }$ as detailed in encapsulation efficiency section. Drug solubility was calculated from Beer-Lambert plots. In case of cinnarizine, drug concentration was assessed in saturated solution according to the HPLC method reported in the previous section.

\section{In vitro drug release from microparticles}

The USP II paddle apparatus (Model PTWS, Pharmatest, Hainburg, Germany) equipped with inline analysis coupled with $0.22 \mu \mathrm{m}$ filter was employed to assess the microparticles' dissolution profiles. Microparticles (0.1g) were accurately weighed and filled into capsule size 0 . Each capsule was placed in a metal sinker to ensure a submerged position in a vessel containing $750 \mathrm{~mL}$ of $0.1 \mathrm{~N} \mathrm{HCl}$ as dissolution medium at $37 \pm 0.5^{\circ} \mathrm{C}$. After $120 \mathrm{~min}, 250$ $\mathrm{mL}$ of $0.2 \mathrm{M}$ tri-sodium phosphate (equilibrated to $37 \pm 0.5^{\circ} \mathrm{C}$ ) was added to the dissolution vessel, and the $\mathrm{pH}$ of the solution was adjusted to $7.4 \pm 0.05$ if necessary using $5 \mathrm{~N} \mathrm{HCl}$ or $4 \mathrm{~N} \mathrm{NaOH}$ solutions, and the dissolution experiment was continued for another 4 hours. Samples were taken every $5 \mathrm{~min}$, the speed of the paddle was $100 \mathrm{rpm}$ and each dissolution test was replicated 3 times. Data were processed using Icalis software (Icalis Data Systems Ltd, Berkshire, UK). A standard calibration curve was prepared for each drug in acidic and 


\section{RESULTS AND DISCUSSION}

\section{Microsphere properties}

All nine drugs were successfully encapsulated into Eudragit L and Eudragit $\mathrm{S}$ microparticles. The particles were spherical and had a uniform size distribution of 25-60 $\mu \mathrm{m}$ and 35-55 $\mu \mathrm{m}$ for Eudragit $\mathrm{L}$ and Eudragit $\mathrm{S}$ respectively (Table 1). Representative SEM images of amprenavir and prednisolone loaded microparticles are shown in Fig.1. According to the SEM images, there was no evidence of porosity in any of the fabricated microparticles. In addition, X-ray powder diffraction and thermal analysis showed no evidence of crystallinity in the microparticles.

Eudragit S microparticles were significantly larger than Eudragit L ones (paired samples ttest, $\mathrm{t}(11)=3.39, \mathrm{p}<0.01)$. A greater size of Eudragit $\mathrm{S}$ microparticles prepared under the same conditions as Eudragit L microparticles was also reported by Kendall et al. (2009) and was attributed to the nature of polymers; the higher viscosity of Eudragit S solution leading to the formation of larger emulsion droplets under the same stirring conditions. The encapsulation efficiency was high for all drugs (60-90\%, Table 1) with Eudragit $\mathrm{S}$ microparticles having slightly (but statistically significantly) higher encapsulation 
efficiencies than Eudragit L microparticles (paired samples t-test, $t(11)=5.76, p<0.0005$ ). The data shows the universal ability of this microparticle system to encapsulate drug molecules with a wide range of physicochemical properties.

\section{In vitro drug release from microparticles}

The release profiles of the nine drugs from Eudragit $\mathrm{S}$ and Eudragit L microparticles are shown in Figs. 2 and 3 respectively. Release of dipyridamole, cinnarizine, amprenavir, bendroflumethiazide, budenoside, prednisolone in acidic medium was well-controlled from both Eudragit S and Eudragit L microparticles, being less than $10 \%$ of the total drug content after $120 \mathrm{~min}$. In contrast, the release of paracetamol, salicylic acid and ketoprofen were poorly controlled ( $>10 \%$ of drug content).

Upon changing the $\mathrm{pH}$ to 6.8 and 7.4 for Eudragit L and Eudragit $\mathrm{S}$ microparticles respectively, rapid and complete drug release was achieved within $20 \mathrm{~min}$ and $45 \mathrm{~min}$ for Eudragit L and Eudragit S respectively for all drugs except for cinnarizine (Figs. 2 and 3). The slower release from Eudragit S microparticles could be due to its larger size (and hence smaller surface area), as well as a slower dissolution of the Eudragit S polymer. A lower dissolution rate of Eudragit S films (compared to Eudragit L ones) has been reported ${ }^{17}$. The limited release of cinnarizine at high $\mathrm{pH}$ is attributed to the poor solubility of the basic drug in phosphate buffer. It was noted that drug crystals appeared in the dissolution medium after $\mathrm{pH}$ change, indicating a rapid precipitation of cinnarizine.

\section{Influence of drug and particle properties on the control of drug release in acid medium}

Plots of drug release versus: i) drug molecular weight, ii) solubility in acidic medium and iii) microsphere size are shown in Figs. 4-6. No clear relationship was found between the solubility of the drug in acid medium or microsphere size and drug release in the acidic medium. In contrast, the drug's molecular weight seemed to have a significant impact on its release, drug release decreasing exponentially with increasing molecular weight. A minimum molecular weight of around $300 \mathrm{Da}$ seems to be necessary for control of drug release in acid medium (Fig. 6). A larger molecular size of the drug is likely to impede its movement through the polymeric network of the microparticle matrix and hence its release in acid medium ${ }^{7}$. The relative importance of the two drug properties, molecular weight and 
drug acid solubility, can be visualised in Figs. 7a-b. The figures clearly illustrate that release of larger drug molecules ( $>300 \mathrm{Da}$ ) are likely to be well-controlled and fulfil the USP criteria for delayed release formulations regardless of the drug's solubility in the medium.

To quantify the different influences, multi-linear regression was conducted, and yielded the following equation:

\section{Drug Released $(\%)=$}

$$
\text { 55.123-0.123 MW+9.7 Log (Sol) }-0.012 d^{2}+1.55 \mathrm{P}
$$

Eq.5

where $\mathrm{MW}=$ drug molecular weight $(\mathrm{Da}), \log (\mathrm{Sol})=$ logarithm of drug saturation solubility in the acidic medium at $37{ }^{\circ} \mathrm{C}$ assessed in $\mathrm{mg} / \mathrm{L}, d=$ Median diameter of microparticles $(\mu \mathrm{m})$ and $\mathrm{P}$ is a constant relating to the polymer, $\mathrm{P}=0$ for Eudragit $\mathrm{S}$ and $\mathrm{P}$ $=1$ for Eudragit $\mathrm{L}$.

It can be seen that drug release was increased by higher drug solubility and reduced by higher drug molecular weight and larger microparticle size. The multiple regression standardized coefficients revealed that molecular weight was by far the most prominent factor in controlling drug release (Standardized coefficient Beta $=-0.617, p<0.001$ ) while drug solubility $($ Beta $=0.403, \mathrm{p}<0.01)$ and microsphere size $($ Beta $=-0.396, p<0.05)$ had smaller influences. The model also suggests that the nature of polymethacrylate polymer (Eudragit S or Eudragit L) has no significant effect in controlling drug release in the acidic medium $(B e t a=0.03, p=0.79)$. According to the model, replacing Eudragit $\mathrm{S}$ with Eudragit $\mathrm{L}$ was expected to increase drug release after two hours in the acid by less than $2 \%$. Equation 5 was able to describe $84 \%$ of the total variance $(F(4,17)=22.111$, p< 0.0005). Other factors not investigated in this study are also expected to affect drug release from polymeric matrix systems such as drug-polymer interactions ${ }^{18-21}$.

\section{CONCLUSIONS}

Nine drugs with different chemical natures were encapsulated in Eudragit L and Eudragit S microparticles using a novel emulsion solvent evaporation method. This showed the universality of the employed method for the preparation of delayed release particulate 
formulations. The particles had the desirable properties of spherical morphology, smooth surface, small microsphere size $(<100 \mu \mathrm{m})$ and a uniform size distribution. However, all the drug-loaded microparticles did not conform to USP specifications with respect to control of drug release in acid medium for delayed release preparations i.e. release of $<10 \%$ of drug content following a 2 hour incubation in an acid medium. Paracetamol, ketoprofen and salicylic acid were released at $>10 \%$. When the influences of the drug's molecular weight, acid solubility and microsphere size on drug release in acid medium were modelled using multiple regression, the drug molecular weight was found to be the most important predictor while the drug's acid solubility and the microsphere size were less influential. 
1. Kawashima Y, Niwa T, Handa T, Takeuchi H, Iwamoto T, Itoh Y 1989. Preparation of prolonged-release spherical micro-matrix of ibuprofen with acrylic polymer by the emulsion-solvent diffusion method for improving bioavailability. Chem Pharm Bull (Tokyo) 37:425-429.

2. Huang HP, Ghebre-Sellassie I 1989. Preparation of microspheres of water-soluble pharmaceuticals. J Microencapsul 6:219-225.

3. Watts PJ, Davies MC, Melia CD 1990. Microencapsulation using emulsification/solvent evaporation: an overview of techniques and applications. Crit Rev Ther Drug Carrier Syst 7:235-259.

4. Kilicarslan M, Baykara T 2004. Effects of the permeability characteristics of different polymethacrylates on the pharmaceutical characteristics of verapamil hyhdrochloride-loaded microspheres. J Microencapsul 21:175-189.

5. Obeidat WM, Price JC 2005. Preparation and in vitro evaluation of propylthiouracil microspheres made of Eudragit RL 100 and cellulose acetate butyrate polymers using the emulsion-solvent evaporation method. J Microencapsul 22:281-289.

6. Obeidat WM, Price JC 2006. Preparation and evaluation of Eudragit S 100 microspheres as $\mathrm{pH}$-sensitive release preparations for piroxicam and theophylline using the emulsion-solvent evaporation method. J Microencapsul 23:195-202.

7. Silva JP FJP 1999. Effect of drug properties on the release from CAP microspheres prepared by a solvent evaporation method. J Microencapsul 16:95-103.

8. Esposito E, Cervellati F, Menegatti E, Nastruzzi C, Cortesi R 2002. Spray dried Eudragit microparticles as encapsulation devices for vitamin $\mathrm{C}$. Int $\mathbf{J}$ Pharm 242:329-334.

9. Raffin RP, Colome LM, Pohlmann AR, Guterres SS 2006. Preparation, characterization, and in vivo anti-ulcer evaluation of pantoprazole-loaded microparticles. Eur J Pharm Biopharm 63:198-204.

10. Raffin RP, Jornada DS, Re MI, Pohlmann AR, Guterres SS 2006. Sodium pantoprazole-loaded enteric microparticles prepared by spray drying: Effect of the scale of production and process validation. Int J Pharm 324:10-18.

11. Obeidat WM, Price JC 2006. Preparation and evaluation of Eudragit S 100 microspheres as $\mathrm{pH}$-sensitive release preparations for piroxicam and theophylline using the emulsion-solvent evaporation method. J Microencapsul 23:195-202.

12. Song M, Li N, Sun S, Tiedt LR, Liebenberg W, de Villiers MM 2005. Effect of Viscosity and Concentration of Wall Former, Emulsifier and Pore-Inducer on the Properties of Amoxicillin Microcapsules Prepared by Emulsion Solvent Evaporation. Il Farmaco 60:261-267. 
13. Nilkumhang S, Basit AW 2009. The robustness and flexibility of an emulsion solvent evaporation method to prepare $\mathrm{pH}$-responsive microparticles. Int $\mathrm{J}$ Pharm in press.

14. Nilkumhang S, Alhnan MA, McConnell E, Basit AW 2009. Drug distribution in enteric microparticles. Int J Pharm In press.

15. Song M, Li N, Sun S, Tiedt LR, Liebenberg W, de Villiers MM 2005. Effect of viscosity and concentration of wall former, emulsifier and pore-inducer on the properties of amoxicillin microcapsules prepared by emulsion solvent evaporation. Farmaco 60:261-267.

16. Kendall R, Alhnan MA, Nilkumhang S, Murdan S, Basit AW 2009. Fabrication and in vivo evaluation of highly $\mathrm{pH}$-responsive acrylic microparticles for targeted gastrointestinal delivery. Eur J Pharm Sci 37:284-290.

17. Lehmann K, Petereit H, Dreher D 1993. Fast disintegrating controlled-release tablets from coated particles. Pharm Ind 55:940-947.

18. Hsiue GH, Liao CM, Lin SY 1998. Effect of drug-polymer interaction on the release characteristics of methacrylic acid copolymer microcapsules containing theophylline. Artif Organs 22:651-656.

19. Jenquin MR, Liebowitz SM, Sarabia RE, McGinity JW 1990. Physical and chemical factors influencing the release of drugs from acrylic resin films. J Pharm Sci 79:811-816.

20. Karavas E, Ktistis G, Xenakis A, Georgarakis E 2006. Effect of hydrogen bonding interactions on the release mechanism of felodipine from nanodispersions with polyvinylpyrrolidone. Eur J Pharm Biopharm 63:103-114.

21. Mortada LM, Bostanian LA, Salib NN 1990. Interactions of oxyphenbutazone with polyvinylpyrrolidone. Pharmazie 45.

\section{List of figures}

Fig. 1. SEM micrograph of amprenavir (1a and 1b), prednisolone (1c and 1d) loaded Eudragit $\mathrm{S}$ and Eudragit L microparticles

Fig. 2. \% drug release from Eudragit L microparticles with time, using a pH-change dissolution method.

Fig. 3. \% drug release from Eudragit $\mathrm{S}$ microparticles with time, using a $\mathrm{pH}$-change dissolution method. 
Fig. 4. \% drug release from microparticles as a function of drug acid solubility (the dotted line represents USP criteria)

Fig. 5. \% drug release from microparticles as a function of microsphere size (the dotted line represents USP criteria)

Fig. 6. \% drug release from microparticles as a function of drug molecular weight (the dotted line represents USP criteria)

Fig. 7. Relative importance of drug molecular weight and drug acid solubility on drug release from (a) Eudragit $\mathrm{S}$ and (b) Eudragit L microparticles after 2 hours in gastric medium (sphere size is proportional to drug molecular weight, the dotted line represents USP criteria).

\section{List of tables}

Table 1: Drug's molecular weight and microsphere size, encapsulation efficiency and percentage drug release in acid medium from Eudragit $S$ and Eudragit L microparticles. 
Table 1

\begin{tabular}{|c|c|c|c|c|c|c|c|c|}
\hline \multirow{2}{*}{ Drug } & \multirow{2}{*}{$\begin{array}{c}\text { Solubility } \\
\text { in acidic } \\
\text { medium } \\
(\mathrm{mg} / \mathrm{L})\end{array}$} & \multirow{2}{*}{$\begin{array}{c}\text { Molecular } \\
\text { weight } \\
\text { (Da) }\end{array}$} & \multicolumn{2}{|c|}{$\begin{array}{c}\text { Particle size } \\
\mathrm{D}(\mathbf{0 , 5}) \pm \mathrm{SD} \mu \mathrm{m}(\text { Span } \pm \text { S.D })\end{array}$} & \multicolumn{2}{|c|}{$\begin{array}{l}\text { Encapsulation efficiency } \\
\qquad(\%) \pm \mathrm{SD}\end{array}$} & \multicolumn{2}{|c|}{$\begin{array}{c}\text { Drug release after } 2 \text { hours } \\
\qquad(\%) \pm \mathrm{SD}\end{array}$} \\
\hline & & & Eudragit $\mathbf{S}$ & Eudragit L & Eudragit $S$ & Eudragit L & Eudragit $S$ & Eudragit L \\
\hline Salicylic acid & $1,435.5$ & 138.1 & $46 \pm 4.2(3.0 \pm 4.0)$ & $31 \pm 1.3(0.7 \pm 0.0)$ & $107.2 \pm 5.1$ & $104 \pm 1.9$ & $40.8 \pm 0.5$ & $86.9 \pm 1.3$ \\
\hline Paracetamol & 12,309 & 151.1 & $38 \pm 1.9(0.8 \pm 0.07)$ & $30 \pm 1.2(1.2 \pm 0.1)$ & $83.5 \pm 0.7$ & $83 \pm 1.0$ & $57.3 \pm 0.3$ & $63.2 \pm 0.4$ \\
\hline Ketoprofen & 75.6 & 254.2 & $36 \pm 1.2(0.9 \pm 0.3)$ & $28 \pm 0.9(0.9 \pm 0.1)$ & $91.1 \pm 1.1$ & $90 \pm 0.9$ & $6.9 \pm 0.8$ & $17.1 \pm 2.9$ \\
\hline Prednisolone & 218 & 360.4 & $48 \pm 1.6(0.6 \pm 0.4)$ & $38 \pm 0.5(0.7 \pm 0.2)$ & $80 \pm 3.2$ & $77 \pm 1.2$ & $1.6 \pm 0.3$ & $7.1 \pm 0.3$ \\
\hline Cinnarizine & $2,110.6$ & 369.5 & $49 \pm 2.4(0.7 \pm 0.1)$ & $56 \pm 6.8(1.2 \pm 0.3)$ & $64 \pm 2.7$ & $62 \pm 1.9$ & $0.0 \pm 0.0$ & $1.5 \pm 0.2$ \\
\hline Bendroflumethiazide & 30.2 & 421.4 & $46 \pm 13.5(1.0 \pm 0.1)$ & $41 \pm 4.1(1.0 \pm 0.1)$ & $68 \pm 0.9$ & $63 \pm 1.0$ & $1.6 \pm 0.3$ & $3.1 \pm 0.1$ \\
\hline Budenoside & 20.0 & 430.5 & $44 \pm 1.6(1.0 \pm 0.2)$ & $33 \pm 0.5(0.7 \pm 0.1)$ & $59 \pm 5.7$ & $53 \pm 1.6$ & $1.7 \pm 0.8$ & $3.4 \pm 0.0$ \\
\hline Dipyridamole & 29,200 & 504.7 & $56 \pm 0.2(0.8 \pm 0.1)$ & $60 \pm 5.9(0.9 \pm 0.1)$ & $75 \pm 1.7$ & $70 \pm 0.8$ & $0.5 \pm 0.4$ & $0.0 \pm 0.0$ \\
\hline Amprenavir & 89.0 & 505.6 & $36 \pm 0.2(0.9 \pm 0.1)$ & $27 \pm 1.1(0.9 \pm 0.2)$ & $68 \pm 3.1$ & $60 \pm 0.8$ & $0.0 \pm 0.0$ & $0.0 \pm 0.0$ \\
\hline
\end{tabular}




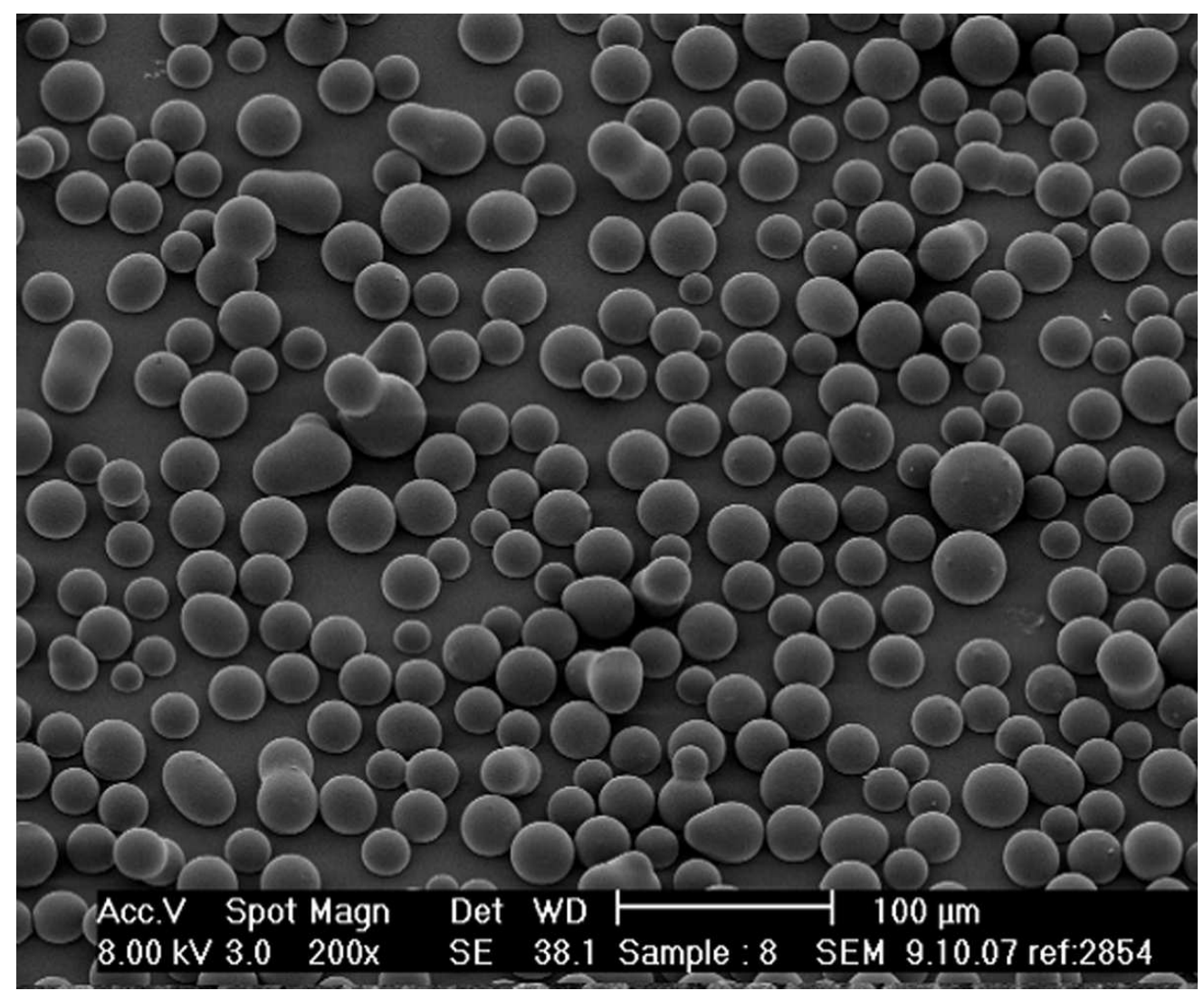

Figure 1a

$423 \times 350 \mathrm{~mm}(72 \times 72$ DPI $)$

John Wiley \& Sons, Inc. 


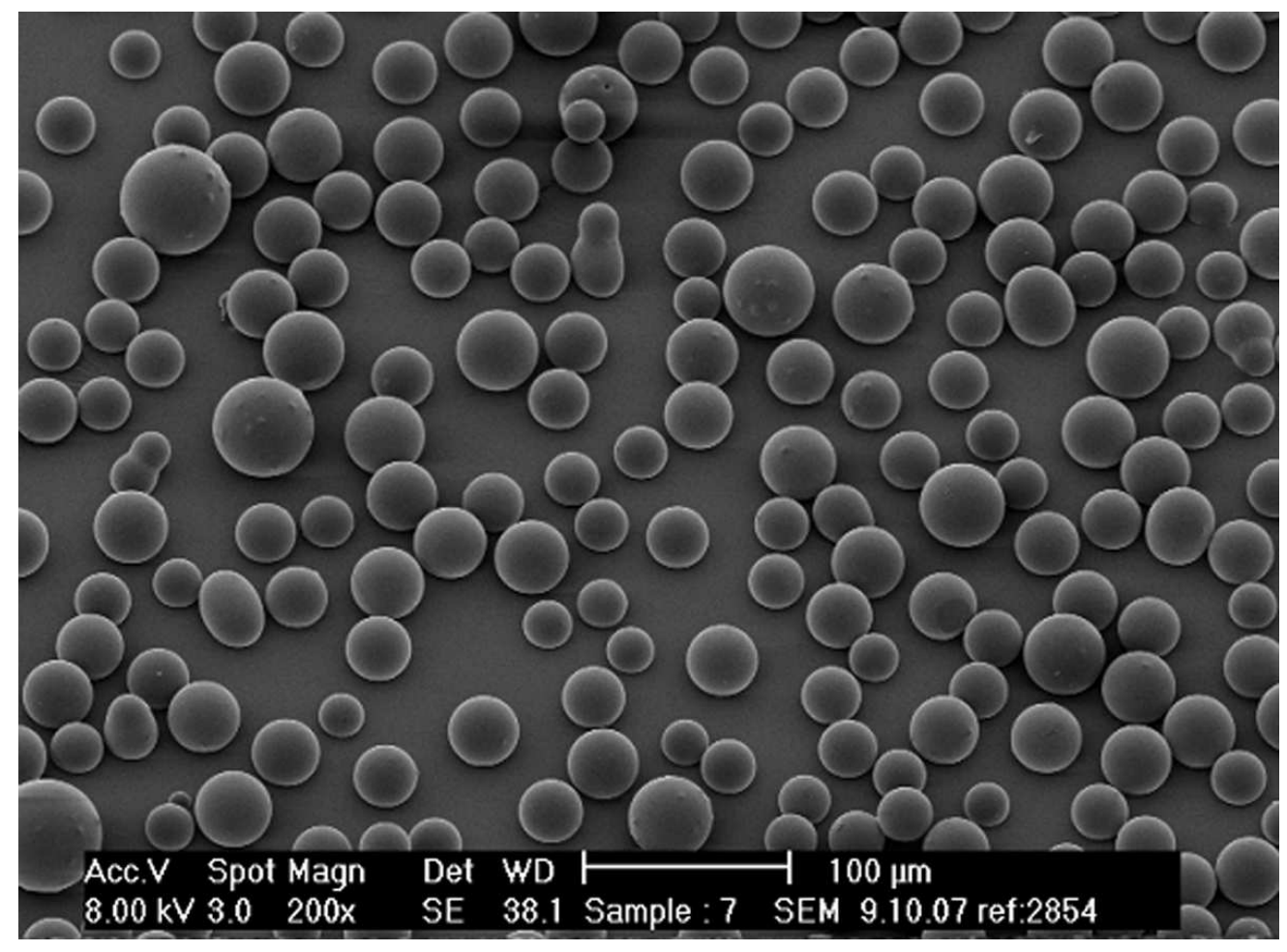

Figure $1 \mathrm{~b}$

$423 \times 311 \mathrm{~mm}(72 \times 72$ DPI $)$

John Wiley \& Sons, Inc. 


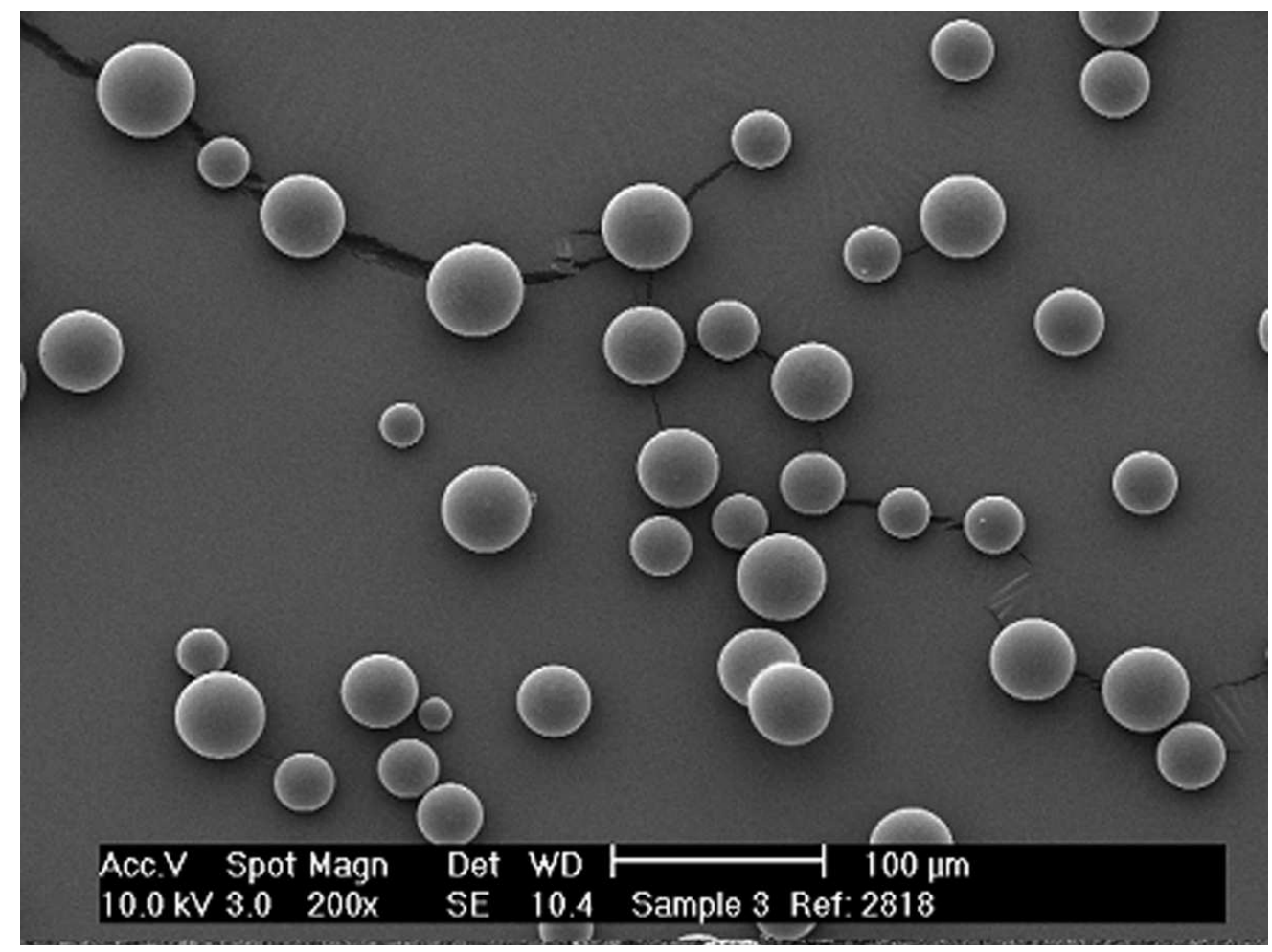

Figure 1c $423 \times 316 \mathrm{~mm}(72 \times 72 \mathrm{DPI})$

John Wiley \& Sons, Inc. 


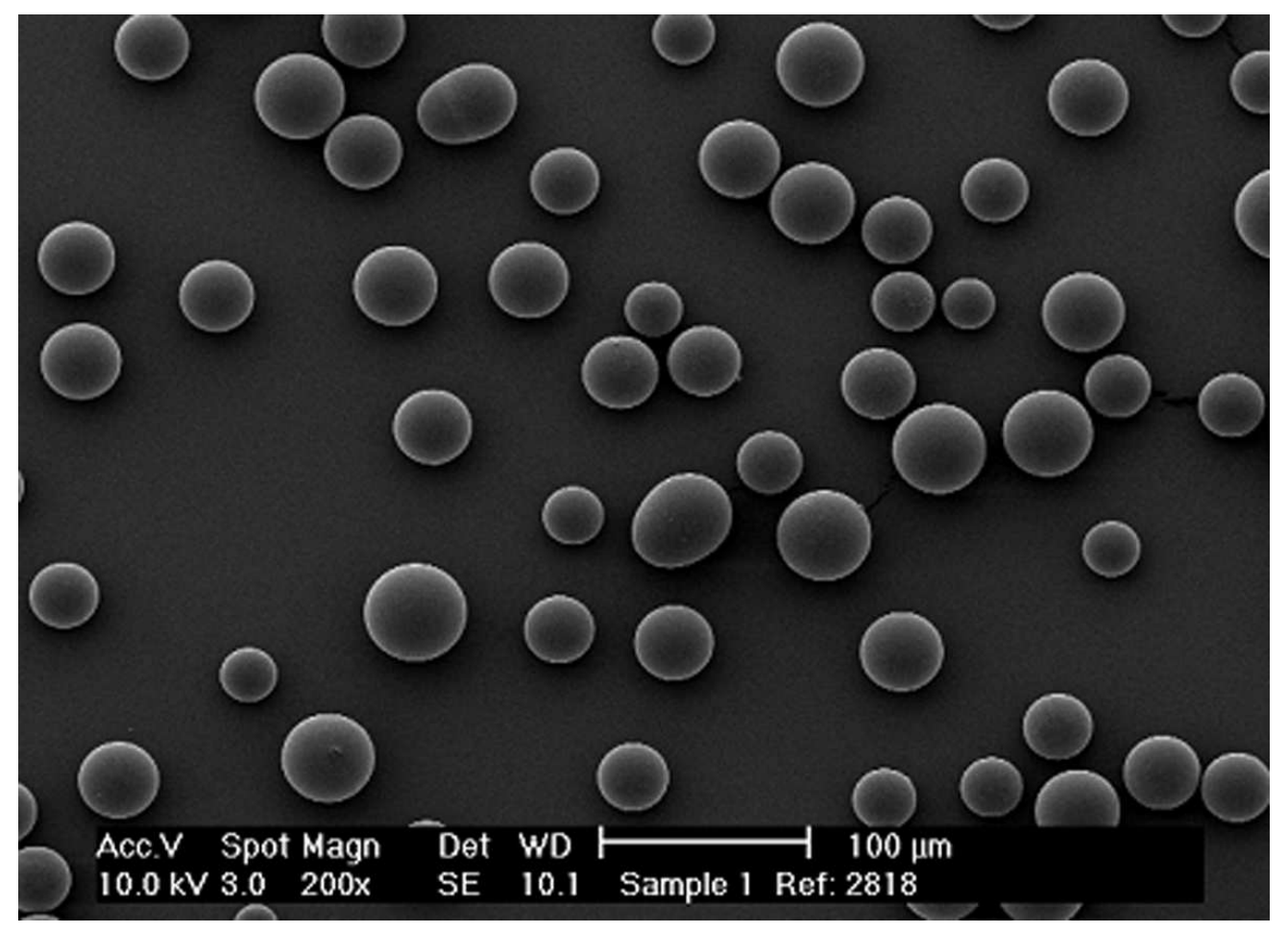

Figure 1d

$423 \times 306 \mathrm{~mm}(72 \times 72$ DPI $)$

John Wiley \& Sons, Inc. 
1

2

3

4

5

6

7

8

9

10

11

12

13

14

15

16

17

18

19

20

21

22

23

24

25

26

27

28

29

30

31

32

33

34

35

36

37

38

39

40

41

42

43

44

45

46

47

48

49

50

51

52

53

54

55

56

57

58

59

60

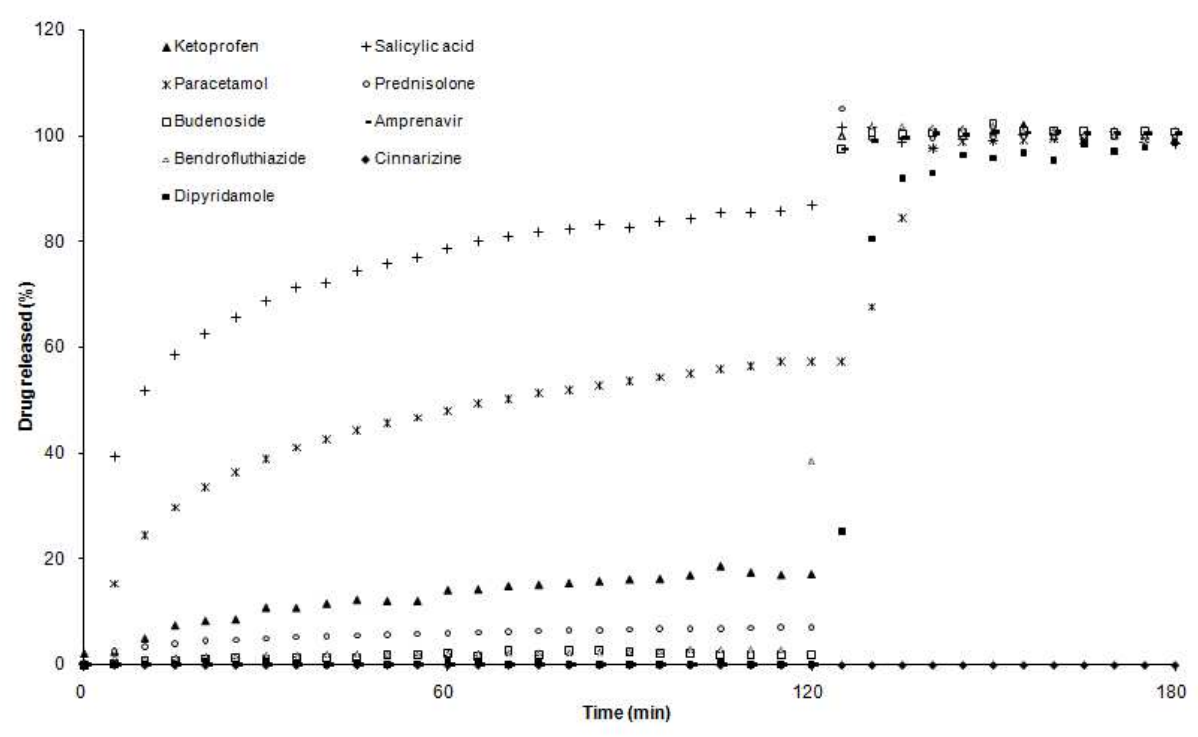

$\%$ drug release from Eudragit $\mathrm{L}$ microparticles with time, using a $\mathrm{pH}$-change dissolution method $230 \times 143 \mathrm{~mm}(96 \times 96 \mathrm{DPI})$

John Wiley \& Sons, Inc. 




$\%$ drug release from Eudragit $\mathrm{S}$ microparticles with time, using a $\mathrm{pH}$-change dissolution method $228 \times 141 \mathrm{~mm}$ (96 x 96 DPI)

John Wiley \& Sons, Inc. 
1

2

3

4

5

6

7

8

9

10

11

12

13

14

15

16

17

18

19

20

21

22

23

24

25

26

27

28

29

30

31

32

33

34

35

36

37

38

39

40

41

42

43

44

45

46

47

48

49

50

51

52

53

54

55

56

57

58

59

60

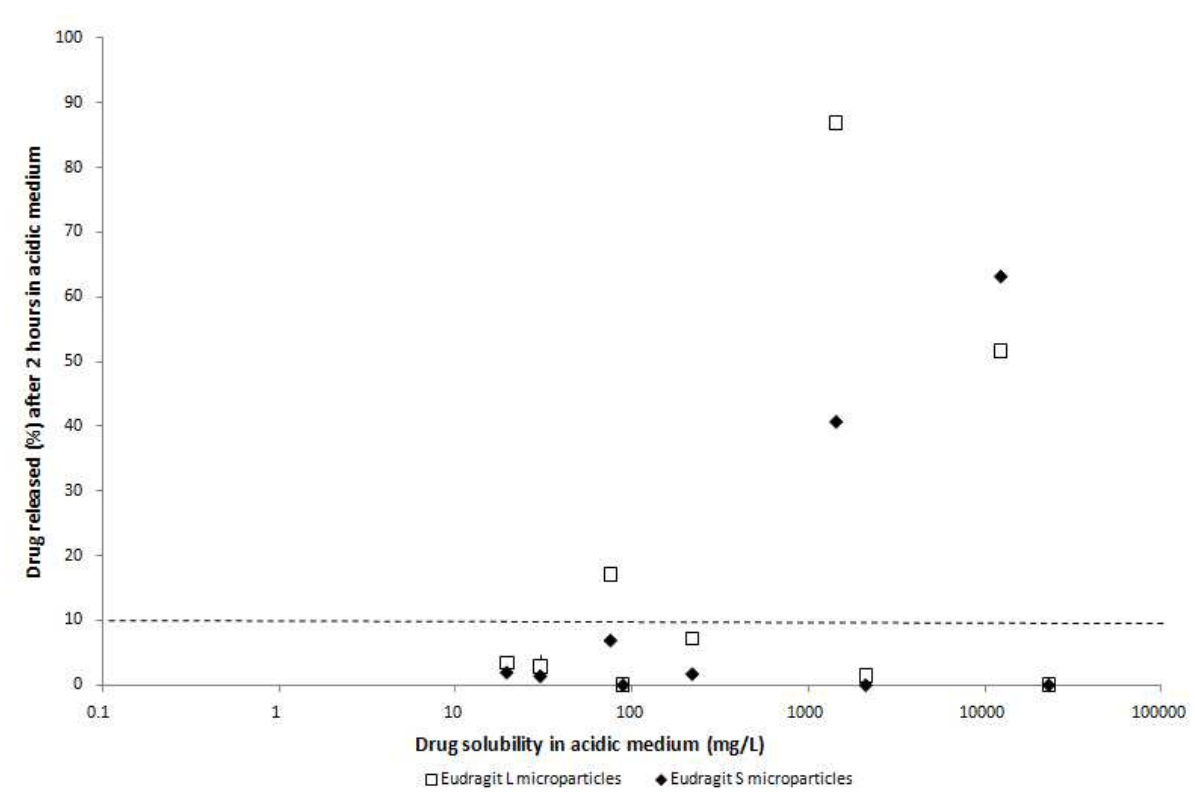

$\%$ drug release from microparticles as a function of drug acid solubility (the dotted line represents USP criteria)

$228 \times 141 \mathrm{~mm}$ (96 x $96 \mathrm{DPI})$

John Wiley \& Sons, Inc. 


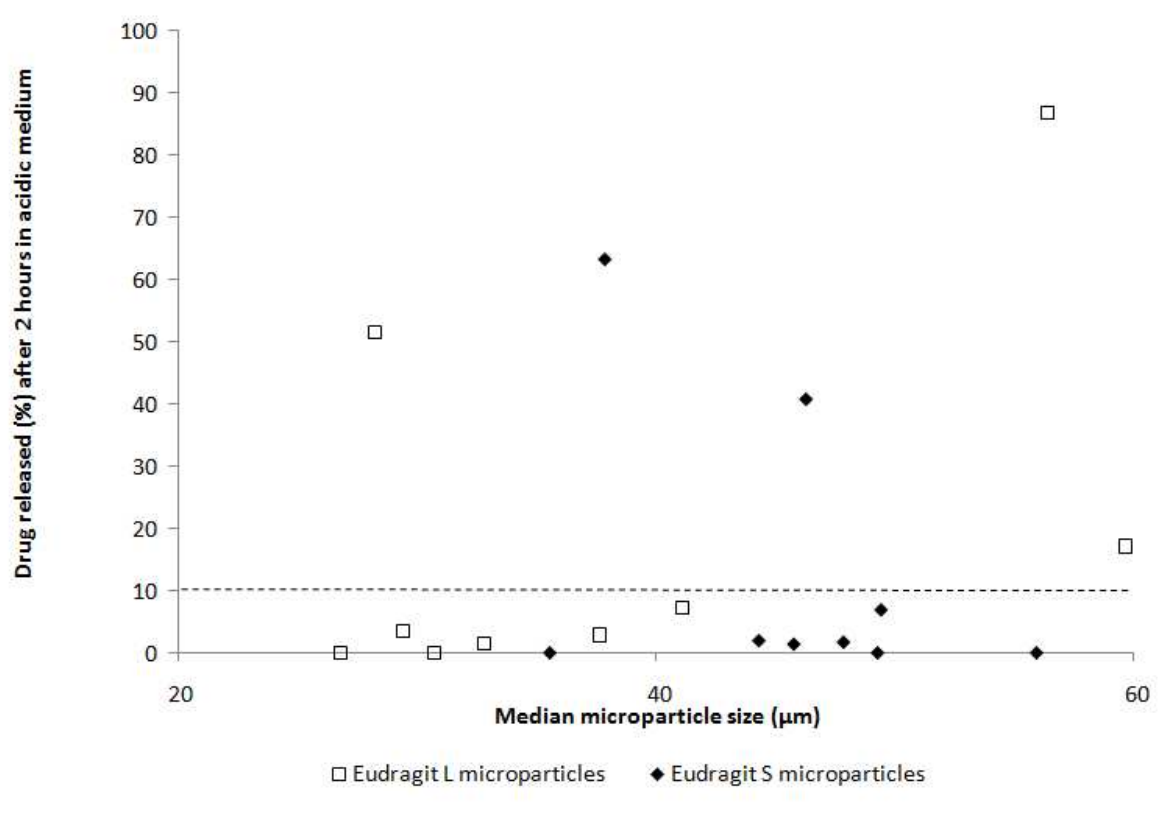

$\%$ drug release from microparticles as a function of microsphere size (the dotted line represents USP criteria) 220x143mm (96 x 96 DPI) 


\section{$\%$ drug release from microparticles as a function of drug molecular weight (the dotted line} represents USP criteria) $220 \times 140 \mathrm{~mm}(96 \times 96 \mathrm{DPI})$

John Wiley \& Sons, Inc. 
Relative importance of drug molecular weight and drug acid solubility on drug release from (a) Eudragit $S$ and (b) Eudragit $L$ microparticles after 2 hours in gastric medium (sphere size is proportional to drug molecular weight, the dotted line represents USP criteria) $211 \times 127 \mathrm{~mm}(96 \times 96 \mathrm{DPI})$ 
Relative importance of drug molecular weight and drug acid solubility on drug release from (a) Eudragit $\mathbf{S}$ and (b) Eudragit L microparticles after 2 hours in gastric medium (sphere size is proportional to drug molecular weight, the dotted line represents USP criteria). $213 \times 126 \mathrm{~mm}(96 \times 96 \mathrm{DPI})$ 